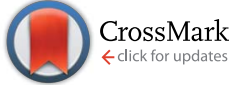

Cite this: RSC Adv., 2016, 6, 103782

Received 4th July 2016

Accepted 21st October 2016

DOI: 10.1039/c6ra17161c

www.rsc.org/advances

\section{Phase segregation in hydroxyfluorapatite solid solution at high temperatures studied by combined $\mathrm{XRD} /$ solid state NMR $\uparrow$}

\author{
Yajie Gao, ${ }^{a}$ Natalia Karpukhina*b ${ }^{*}$ nd Robert V. Law*a
}

Fluoride substituted apatite is a key player among currently existing biomaterials. The ${ }^{19} \mathrm{~F}$ MAS-NMR is perhaps the most and only reliable technique to detect fluoride substitution in apatite. Typically any ${ }^{19} \mathrm{~F}$ MAS-NMR signal between -101.0 and $-107.0 \mathrm{ppm}$ is often used to identify fluoride substitution in apatite. Until now no explanation has been given as to why there is such a large variation in the NMR signals of these crystalline species. In this study, for the first time, we were able to explain this large variation in the ${ }^{19} \mathrm{~F}$ chemical shift values often seen in the literature. Hydroxyfluorapatites (FHA) with varied fluoride substitution and free from other substitutions have been synthesized via solution route followed by heat treatment in air at different temperatures up to $900{ }^{\circ} \mathrm{C}$. Solid-state nuclear magnetic resonance $\left({ }^{19} \mathrm{~F}\right.$ and ${ }^{31} \mathrm{P}$ MAS-NMR) and X-ray diffraction (XRD) were used to characterize the synthesized powder samples. Formation of solid solution with varied hydroxyl/fluoride ratio was observed after the heat treatment up to a temperature of $300{ }^{\circ} \mathrm{C}$. FHA samples decomposed to $\beta$-tricalcium phosphate $(\beta$ TCP) at higher temperature, which started from $20 \% \mathrm{~F}$ sample at $750{ }^{\circ} \mathrm{C}$. With increasing $\mathrm{F} \%$, the $\mathrm{FHA}$ became more thermally stable and $80 \% \mathrm{~F}$ sample did not show $\beta$-TCP until $900{ }^{\circ} \mathrm{C}$. An empirical nonlinear correlation between ${ }^{19} \mathrm{~F}$ NMR chemical shift and relative $\mathrm{F} \%$ had been established. The mechanism of FHA solid solution formation and its thermal instability is proposed.

\section{Introduction}

Fluoride substituted hydroxyapatite (FHA) $\left[\mathrm{Ca}_{10}\left(\mathrm{PO}_{4}\right)_{6}\right.$ $\left.\mathrm{F}_{2 x}(\mathrm{OH})_{2-2 x}(0 \leq x \leq 1)\right]$ is a well-known biomaterial and also constitutes the biomineral part of normal dental and bone formation in the body. ${ }^{\mathbf{1}}$ It occurs naturally in tooth enamel, however, here it contains $\mathrm{F}$ ions, replacing $\mathrm{OH}^{-}$, as high as 50 $\mathrm{mol} \%$ in the inorganic apatite component $\left[\mathrm{Ca}_{10}\left(\mathrm{PO}_{4}\right)_{6}(\mathrm{OH} / \mathrm{F})_{2}\right]^{2}{ }^{2}$ This natural FHA provides the low solubility and good acid resistance to the enamel surface. ${ }^{3}$ In bone, approximately $1 \mathrm{wt} \%$ $\mathrm{F}^{-}$can be found in the inorganic component, which helps prevent a reduction in bone density. ${ }^{4}$ Due to these biological benefits FHA can be utilized as implant material for bone and dental restorations. ${ }^{3}$ In addition, the fluoridation level of FHA is crucial in biomedical applications because of its effects on the crystallization, solubility and thermal stability of the bulk apatitic material.

\footnotetext{
${ }^{a}$ Department of Chemistry, Imperial College London, South Kensington Campus, Exhibition Road, London SW7 2AZ, UK. E-mail: r.law@imperial.ac.uk

${ }^{b}$ Dental Physical Sciences, Institute of Dentistry, Barts and The London School of Medicine and Dentistry, Queen Mary University of London, London E1 4NS, UK. E-mail:n.karpukhina@qmul.ac.uk

$\uparrow$ Electronic supplementary information (ESI) available: Table S1 $a$ axis fitting results (PDF). See DOI: 10.1039/c6ra17161c
}

FHA has the similar crystal lattice to hydroxyapatite (HA) which belongs to the hexagonal crystal system with the space group $P 6_{3} / m$. Along the $c$ axis, $F$ atoms are located at the center of Ca(II) triangles on the mirror plane at $z=1 / 4$ and $3 / 4 .^{5}$ When $\mathrm{F}^{-}$substitutes for $\mathrm{OH}^{-}$in $\mathrm{c}$ channel, due to the smaller ionic radius of $\mathrm{F}^{-}$(ionic radii of the $\mathrm{OH}^{-}$and $\mathrm{F}^{-}$are 1.68 and $1.32 \AA$ respectively), a contraction of the $a$ axis in lattice structure is generated, while no significant changes occur to the $c$ axis as the positions of the two sets of $\mathrm{Ca}^{2+}$ and the $\mathrm{PO}_{4}{ }^{3-}$ in FHA are nearly identical to those of HA. ${ }^{6} \mathrm{X}$-ray diffraction (XRD) analysis have found that the (002) peak of FHA is shifted to the left (towards the lower angle) and (300) peak is shifted to the right (towards the higher angle) comparing with the pattern of HA, which indicates the decrease of $a$ axis of the HA lattice when $\mathrm{F}^{-}$ substitutes for the $\mathrm{OH}^{-}$along the channel. ${ }^{7}$ The merging of (211) and (112) peak of the FHA pattern also suggests the formation of FHA solid solution. ${ }^{3 a, 8}$

Although crystallographic studies of the FHA and HA have been carried out previously, it is still a challenge to distinguish the different fluoridation levels of FHA using solely XRD because these apatites are isostructural, the crystals are typically too small to be detected petrographically or by X-ray diffraction, because of Scherrer broadening effects. In addition, detection of the light elements such as $\mathrm{F}, \mathrm{O}$ and $\mathrm{H}$ is known as to be problematic for the powder XRD technique. ${ }^{9}$ Other techniques have been applied to solve this problem. Energy Dispersive 
Spectroscopy (EDS) and atom probe tomography (APT) can be used to quantify the total amount of $\mathrm{F}^{-}$ions in the samples, ${ }^{2,7,10}$ but fail to distinguish the specific amount of $\mathrm{F}^{-}$in different chemical environments, and is not accurate enough to quantify the amount of $\mathrm{F}^{-}$ions in the channel. Fourier transform infrared spectroscopy (FTIR) has found that on introduction of $\mathrm{F}^{-}$, the $\mathrm{OH}^{-}$librational modes $\left(631 \mathrm{~cm}^{-1}\right)$ shifts to higher wavenumbers up to $747 \mathrm{~cm}^{-1}$ depending on the number of $\mathrm{OH}$ groups in the sections between $\mathrm{F}^{-}{ }^{\mathbf{1 1}}$

High-resolution solid state magic angle spinning (MAS) nuclear magnetic resonance (NMR) has proven to be a sensitive local probe of atomic and molecular structure. ${ }^{12}$ The ${ }^{31} \mathrm{P}$ NMR investigations showed that NMR can be used to identify phosphorus sites from either different protonated phosphate groups or various calcium phosphate species in glasses and ceramics. ${ }^{13}$ ${ }^{1} \mathrm{H}$ MAS-NMR study suggested that the presence of fluorine causes perturbations of the hydrogen environments, and the weak hydrogen bonding between $\mathrm{F}^{-}$and $\mathrm{OH}^{-}$could exist. ${ }^{\mathbf{1 4}}$

The ${ }^{19} \mathrm{~F}$ NMR is one of the few techniques available that unambiguously detects presence of the fluoridated apatite, whether the solid is crystalline, amorphous or fluoride was adsorbed $^{13 a, 15}$ from the media even at low level, though the latter would require longer acquisition time. Some research also states that besides the dominant signal from the channel ions, a second $\mathrm{F}^{-}$environment is present in the carbonate substituted apatite. ${ }^{\mathbf{1 6}}$

Thermal behavior of apatite has been extensively studied due to the increasing interest of adding apatite coating onto the metal surface, which involves high temperature process. ${ }^{16 b}$ Calcined HA at $900{ }^{\circ} \mathrm{C}$ shows a substantial increase in crystallinity, ${ }^{9}$ and continual heating to $1000{ }^{\circ} \mathrm{C}$ reveals partial decomposition to $\beta$-tricalcium phosphate ( $\beta$-TCP). ${ }^{17}$ This $\beta$-TCP phase formation could destabilize the apatite lattice causing lattice parameter $a$ and the unit cell volume to increase. ${ }^{11 b}$

The purpose of the current study is to establish an unequivocal method to distinguish different fluoridation levels of HA by combining XRD and high-resolution MAS-NMR spectra. This study was carried out in order to investigate the hydroxyl and fluorine ordering along the channel and to understand whether the hydroxyl groups and fluoride ions are completely disordered over the positions or whether there is a local ordering of the groups/domains. Moreover, based on the presented experimental data, the effect of different heattreatment temperatures on the FHA structure will be discussed and further understanding of the mechanism of the FHA formation and its stability will be proposed.

\section{Experiment details}

\section{Preparation of HA and FHA}

HA was synthesized by the precipitation method: ${ }^{18}$ diammonium hydrogen phosphate (VWR) $3 \mathrm{M}$ aqueous solution (solution $\mathrm{B}$ ) was added dropwise to calcium nitrate tetrahydrate (Sigma-Aldrich) 1.7 M aqueous solution (solution A). The $\mathrm{pH}$ of the mixture was kept at 11 by adding concentrated ammonia solution (Sigma-Aldrich). To avoid carbonate contamination the reaction was kept in the inert $\mathrm{N}_{2}$ atmosphere for 3 hours. A similar procedure was used for the FHA precipitation by adding extra the ammonium fluoride (Sigma-Aldrich) to the solution B. All the reagents were commercially available and all the aqueous solutions were prepared in atmosphere without further purification. The precipitated powder was filtered using a Büchner funnel and washed by distilled water twice to remove the remaining nitrate and ammonia, then dried at $60{ }^{\circ} \mathrm{C}$ for 12 hours. The dried powder was heated in a furnace at $10{ }^{\circ} \mathrm{C} \mathrm{min}{ }^{-1}$ heating rate to the different heat treatment temperatures and held there for 2 hours and then was allowed to cool in the furnace. The heat treatment temperatures in the range from 300 to $900{ }^{\circ} \mathrm{C}$ were evaluated. The amount of fluoride substitution was varied from 20 to $100 \%$ and the samples with excess of the substitution were also considered, i.e. $200 \%$ of substitution.

\section{Powder X-ray diffraction and solid state NMR characterisation}

The specimens were analyzed using X-ray diffraction using a diffractometer (Bruker D2 Powder Diffractometer). Cu- $\mathrm{K}_{\alpha}$ radiation $(0.154056 \mathrm{~nm})$ at $40 \mathrm{kV} / 40 \mathrm{~mA}$ was used. The diffraction pattern was taken in the $2 \theta$ range of $10^{\circ}$ to $80^{\circ}$ with a step size of $0.04^{\circ}$. XRD Rietveld refinements were carried out by using Profex 3.5.0 with the program BGMN. ${ }^{19}$

High-resolution solid-state ${ }^{19} \mathrm{~F}$ and ${ }^{31} \mathrm{P}$ magic angle spinning (MAS) nuclear magnetic resonance (NMR) spectra of FHA have been obtained on a $600 \mathrm{MHz}$ Bruker Avance NMR spectrometer (14.1 Tesla), operating at $242.9 \mathrm{MHz}$ for ${ }^{31} \mathrm{P}$ and $564.7 \mathrm{MHz}$ for ${ }^{19} \mathrm{~F}$ using low fluorine background probe. The chemical shift references were $85 \%$ solution of phosphoric acid as the primary reference for the ${ }^{31} \mathrm{P}$ and the $1 \mathrm{M} \mathrm{NaF}$ solution with the signal at $-120 \mathrm{ppm}$ for the ${ }^{19} \mathrm{~F}$. Powdered samples were packed into a 2.5 $\mathrm{mm}$ zirconia rotor and spun at the magic angle to remove anisotropy effects. The ${ }^{19} \mathrm{~F}$ and ${ }^{31} \mathrm{P}$ MAS-NMR spectra of the samples were recorded at spinning frequencies $21 \mathrm{kHz}$ and the measurements were done using $60 \mathrm{~s}$ recycle delay. The ${ }^{31} \mathrm{P}$ and ${ }^{19}$ F MAS NMR spectra were deconvoluted using dmfit software package. $^{20}$

\section{Results}

\section{XRD}

The XRD patterns of the FHA powders with different F\% heat treated at 300, 750 and $900{ }^{\circ} \mathrm{C}$ are shown in Fig. 1. All patterns show the characteristic apatite phases, with peaks at $26.0^{\circ}(002)$ and $32.0^{\circ}$ (211). With increasing heat treatment temperature, the diffraction peaks become narrower. At $300{ }^{\circ} \mathrm{C}$ (Fig. 1(a)), all the samples contain single apatite phase, with other phases below detectable levels. However, in $750{ }^{\circ} \mathrm{C}$ series samples shown in Fig. 1(b), in addition to the apatite phase, the $20 \% \mathrm{~F}$ sample shows the peaks at $28.0^{\circ}, 31.0^{\circ}, 34.5^{\circ}$ which are the characteristic reflections of $\beta$-TCP.

The diffraction lines of the mixed FHA samples at this heat treatment temperature are broader than of the HA and some overlap. Furthermore, the width of the diffraction line decreases with increasing fluoride content and reached minimum in the $200 \%$ F sample. In $900{ }^{\circ} \mathrm{C}$ samples Fig. 1(c), all the samples contain apatite phases, and 20 to $80 \% \mathrm{~F}$ samples also show $\beta$ - 


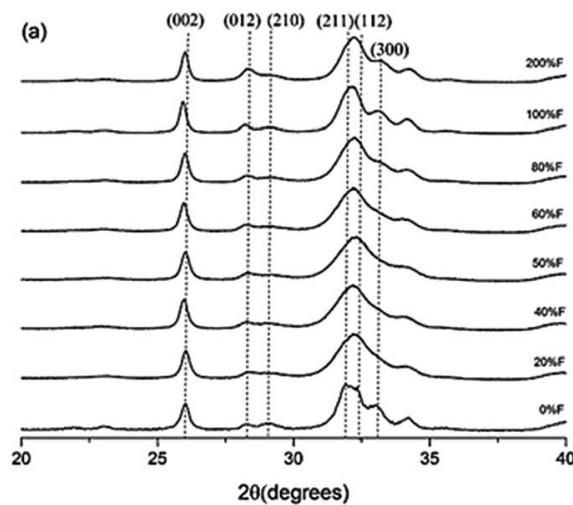

(b)

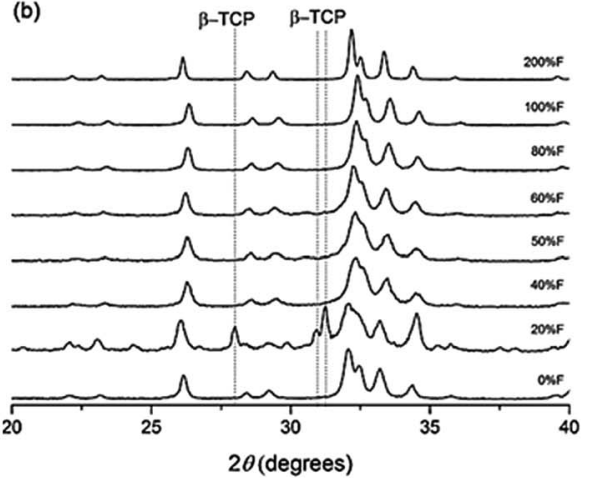

(c)

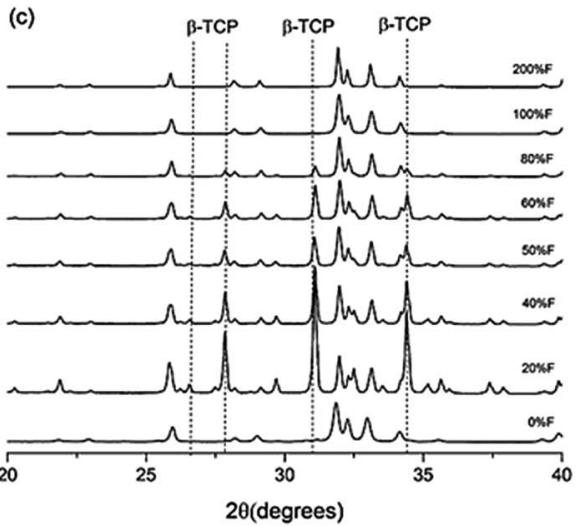

Fig. 1 XRD patterns of (a) 300 (b) 750 and (c) $900{ }^{\circ} \mathrm{C}$ samples. The $h, k$, $l$ indices shown in (a) are also true for the diffraction lines in (b) and (c).

TCP diffraction lines. The intensity of the $\beta$-TCP peaks at $28.0^{\circ}$, $31.0^{\circ}, 34.5^{\circ}$ decreases with increasing $\mathrm{F} \%$.

Refined structural parameters obtained for all samples from the XRD Rietveld refinement are reported in Table 1. $R_{\mathrm{wp}}, R_{\exp }$ and $R^{2}$ for refinements indicate the quality of the fits. The unit cell of HA belongs to the hexagonal crystal with space group $P 6_{3} /$ $m$. The $c$ axis parameter of the most of the samples is around $6.88 \AA$, and the values show little effect with the different $\mathrm{F} \%$ or increasing the heat treatment temperature. In comparison, the $a$ axis values are varied with the amount of $\mathrm{F} \%$ and this also remains true for the heat treated samples, see the plotted in the Fig. 2. For two end members: HA $(0 \% \mathrm{~F})$ and FA $(100 \% \mathrm{~F})$ samples, the increase in heat treatment temperature had little

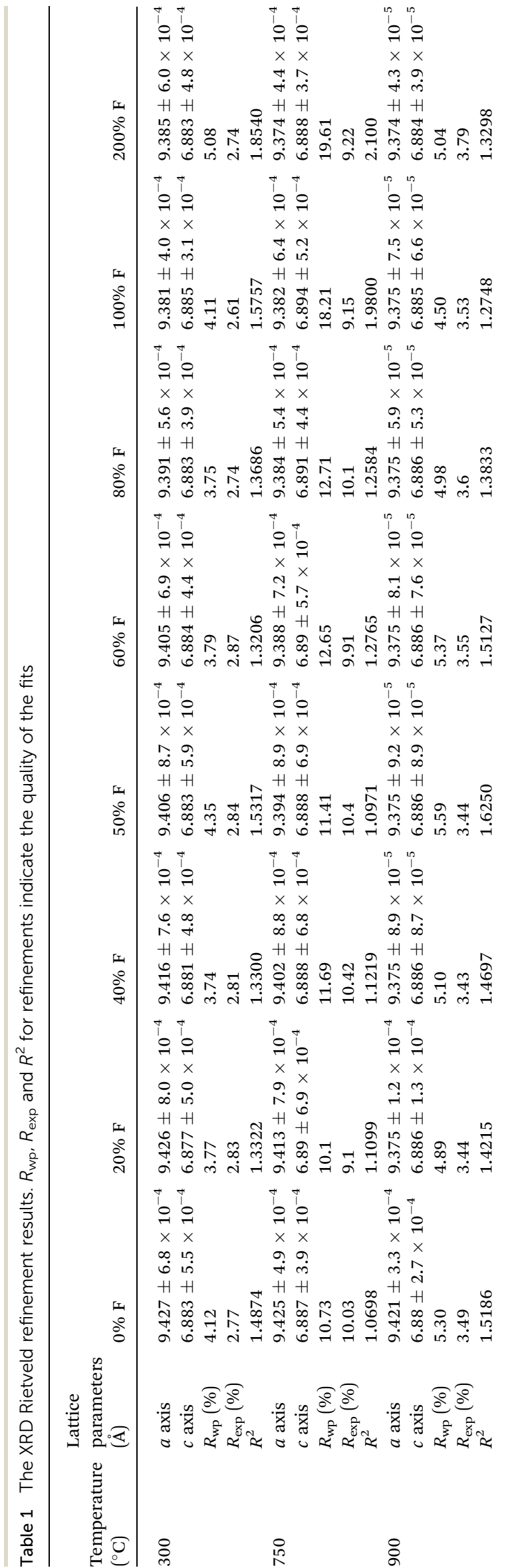




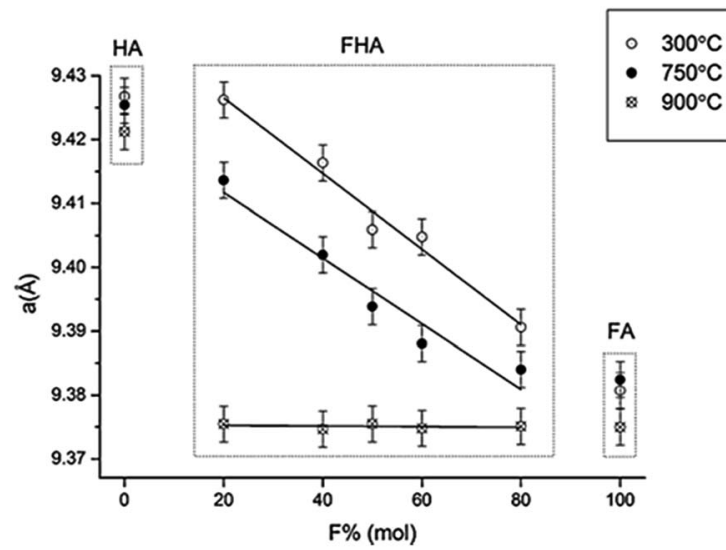

Fig. 2 a axis unit cell parameter plotted against $\mathrm{F} \%$, a axis reducing with increasing $\mathrm{F} \%$ but becoming independent of $\mathrm{F} \%$ in $900{ }^{\circ} \mathrm{C}$ series. The lines represent linear fits of the data. The equations are given in ESI Table S1.†

influence on the $a$ axis parameter compared to the FHA samples. The $a$ axis values are $9.425 \pm 0.05$ and $9.380 \pm 0.05 \AA$ for HA and FA, respectively. For the FHA samples heat treated at 300 and $750{ }^{\circ} \mathrm{C}$, the $a$ axis reduces linearly with increasing $\mathrm{F} \%$. However, when heat treatment temperature increases to $900{ }^{\circ} \mathrm{C}$, the $a$ axis of FHA with different $\mathrm{F} \%$ remained practically constant at $9.380 \AA$ A. The linear fitting results are presented in ESI Table S1. $\dagger$

The results of the quantitative analysis of the XRD patterns are plotted in Fig. 3. At $750{ }^{\circ} \mathrm{C}$, most of samples contain single apatite phase, except $20 \% \mathrm{~F}$ which also contains more than $50 \% \beta$-TCP. With increasing heat treatment temperature, up to $900{ }^{\circ} \mathrm{C}$, the fraction of apatite phase diminishes, in the range of the $\mathrm{F}^{-}$substitution from 20 to $80 \%$. The $20 \% \mathrm{~F}$ sample contains $15 \%$ apatite, which is less than the others, while the $80 \% \mathrm{~F}$ one has the greatest amount of apatite in all of the FHA samples at $900{ }^{\circ} \mathrm{C}$, which is about $70 \mathrm{~mol} \%$.

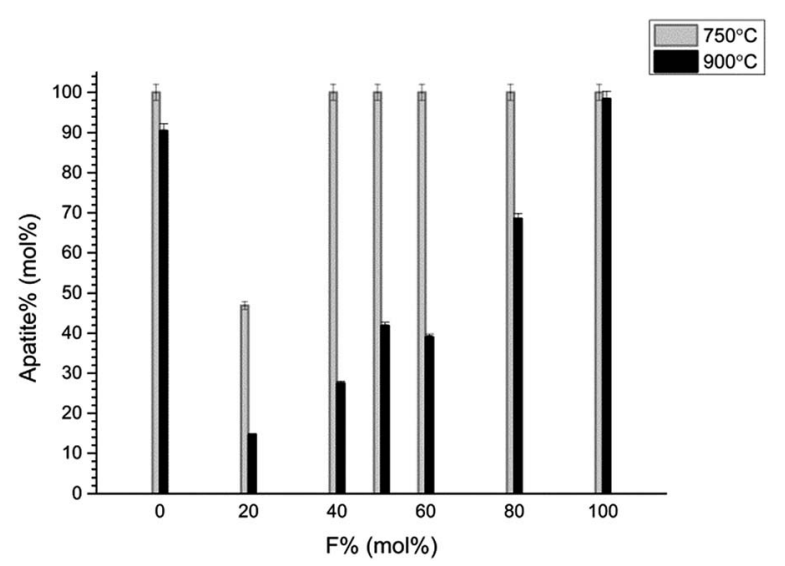

Fig. 3 Comparison of the amount of apatite phase between 750 (grey bar) and $900{ }^{\circ} \mathrm{C}$ (black bar), most of XRD patterns at $750{ }^{\circ} \mathrm{C}$ contain single apatite phase; most of apatite phases at $900{ }^{\circ} \mathrm{C}$ show decomposition (20 to $80 \% \mathrm{~F}$ ).

\section{${ }^{31} \mathbf{P}$ MAS-NMR}

The ${ }^{31} \mathrm{P}$ MAS-NMR spectra from the single-pulse experiments of all the samples at the heat treatment temperatures of 300 and $900{ }^{\circ} \mathrm{C}$ are dominated by a NMR line at $2.8 \mathrm{ppm}$ (Fig. 4). This peak has been previously assigned to the bulk phosphate groups $\mathrm{PO}_{4}{ }^{3-}$ in many other types of apatites. ${ }^{\mathbf{1 3 d , 2 1}}$ The ${ }^{31} \mathrm{P}$ MASNMR spectra of heat treatments of 600 and $750{ }^{\circ} \mathrm{C}$ are similar to the spectra of $300{ }^{\circ} \mathrm{C}$. However, at the heat treatment temperature of $900{ }^{\circ} \mathrm{C}$, another broad resonance around 0.1-5.0 ppm was observed in 20 to $80 \% \mathrm{~F}$ samples, which corresponds to the $\beta$-TCP (Fig. 4(b)). ${ }^{22}$ Fig. 5 plots the full width at half maximum (fwhm) of the ${ }^{31} \mathrm{P}$ NMR signals versus $\mathrm{F}$ content: the ${ }^{31} \mathrm{P}$ peak narrows with increasing heat treatment temperature from 300 to $900{ }^{\circ} \mathrm{C}$. At the highest heat treatment temperature $900{ }^{\circ} \mathrm{C}$, the fwhm stabilised at $0.22 \mathrm{ppm}$, and the amount of $\mathrm{F}$ in the samples shows little effect on the linewidth.

\section{${ }^{19}$ F MAS-NMR}

${ }^{19} \mathrm{~F}$ MAS-NMR spectra for $300{ }^{\circ} \mathrm{C}$ samples are dominated by a resonance line between -103.0 to $-107.0 \mathrm{ppm}$ corresponding

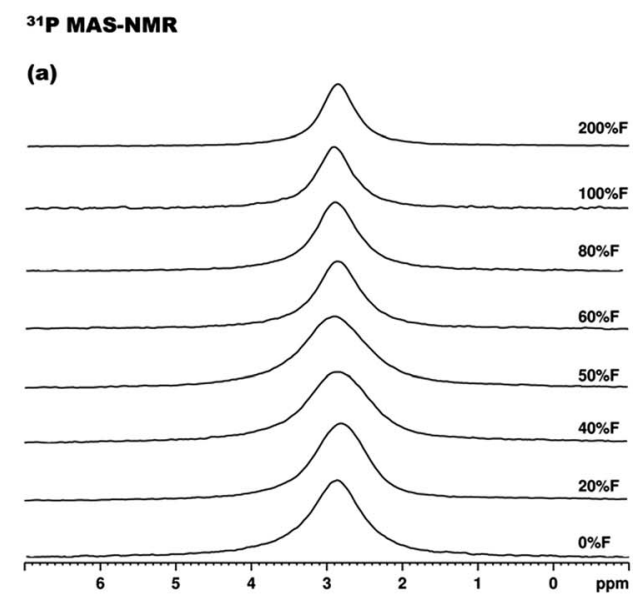

(b)

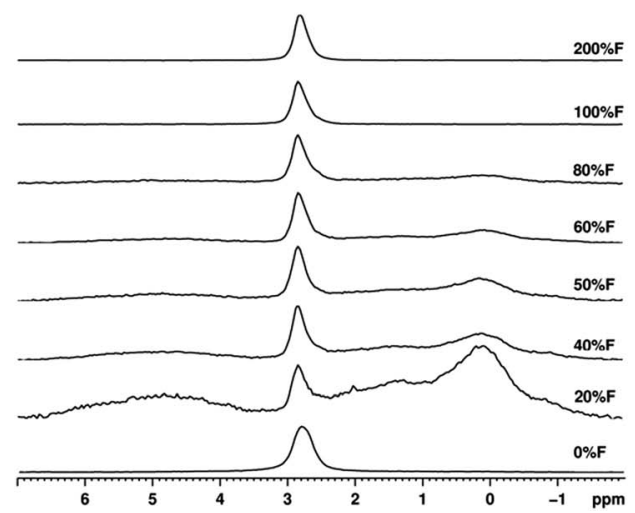

Fig. $4{ }^{31} \mathrm{P}$ MAS-NMR spectra of FHA (a) heat treated at $300{ }^{\circ} \mathrm{C}$, main resonance centred at $2.8 \mathrm{ppm}$ corresponding to the $\mathrm{PO}_{4}{ }^{3-}$ in apatite structure (b) heat treated at $900{ }^{\circ} \mathrm{C}$, the main resonance at $2.8 \mathrm{ppm}$, another additional broad resonance at $0.1-5.0 \mathrm{ppm}$ corresponding to $\mathrm{PO}_{4}{ }^{3-}$ in $\beta$-TCP are observed in 20 to $80 \% \mathrm{~F}$. 


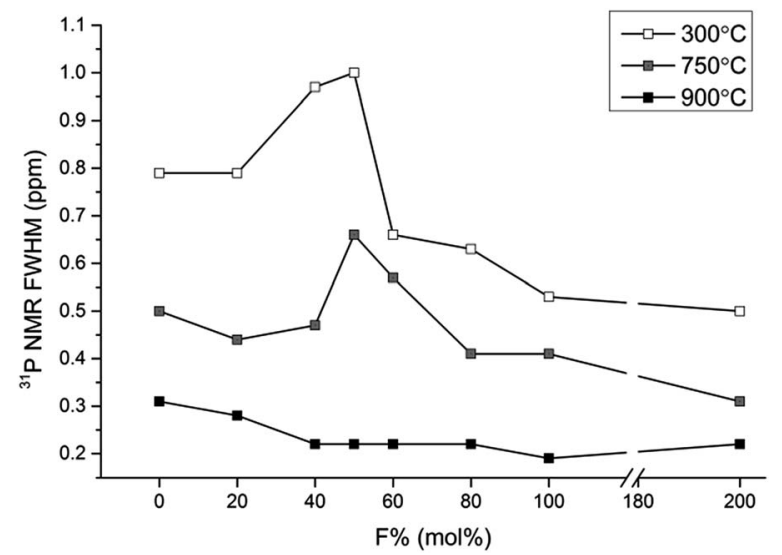

Fig. 5 The fwhm of ${ }^{31} \mathrm{P}$ MAS-NMR signal of FHA heat treated at 300 , 750 and $900{ }^{\circ} \mathrm{C}$. The linewidth narrows with increasing heat treatment temperature, at $900{ }^{\circ} \mathrm{C}$, the fwhm stabilizes at $0.22 \mathrm{ppm}$.

to the $\mathrm{F}^{-}$in the channel but within slightly different chemical environments (Fig. 6(a)). ${ }^{19} \mathrm{~F}$ NMR spectra of 600 and $750{ }^{\circ} \mathrm{C}$ are shown in Fig. 6(b) and (c). The chemical shift (CS) shifts downfield from -106.0 to $-103.0 \mathrm{ppm}$ with increasing the $\mathrm{F} \%$. Most of the signals are clearly asymmetric indicating overlap of several signals, thus, spectra deconvolution was applied to gain quantitative information. The deconvolution results are listed in Table 2. Since it was found that most of these samples contain two signals at -103.0 and $-105.0 \mathrm{ppm}$, the spectra in Fig. 6(b) and (c) were fit using these two resonances. The assignment of these signals is given further in the discussion. From the abundance of each given in Table 2, it is seen that the amount of the $-\mathbf{1 0 3 . 0} \mathrm{ppm}$ structure increases with increasing $\mathrm{F} \%$. When the heat treatment temperature reaches $900{ }^{\circ} \mathrm{C}$, similar spectra are observed in all of the samples with two peaks at -102.0 and -104.0 ppm in Fig. 6(d). The main resonance is $-102.0 \mathrm{ppm}$ contributing to $94 \%$ of spectral intensity and this amount is independent of the $\mathrm{F} \%$. The resonance line at $-109.0 \mathrm{ppm}$ in $200 \% \mathrm{~F}$ sample corresponds to $\mathrm{CaF}_{2}$, which is by-product of the synthesis. It is only present at the high $\mathrm{F}$ content samples ( $\geq$ than $100 \% \mathrm{~F}$ ).

\section{Discussion}

The mechanism of fluoride ions incorporated into hydroxyapatite with increasing heat-treatment temperature

The presented experimental results revealed the formation of different types of FHA depending on the fluoride substitution and heat treatment temperature. The formation of random substitution solid solution is seen at relatively low heat treatment temperature. The separation phenomena occurred at higher heat treatment temperatures depending on $\mathrm{F}^{-}$substitution level. The separation is understood here as a formation of the fluoride-deficient (Fd) and fluoride-rich (Fr) structure domains. Where the Fr is closely approximates a fluorapatitetype structure, in contrast to Fd regions which are similar to the random substituted solid solution, though with the lower fluoridation level. Finally, the extreme case of the separation
19F MAS-NMR

(a)

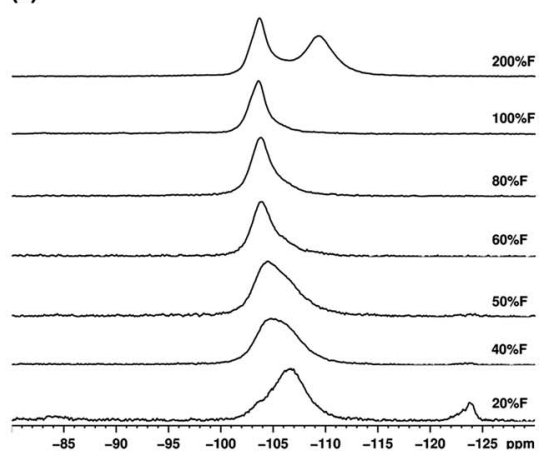

(b)

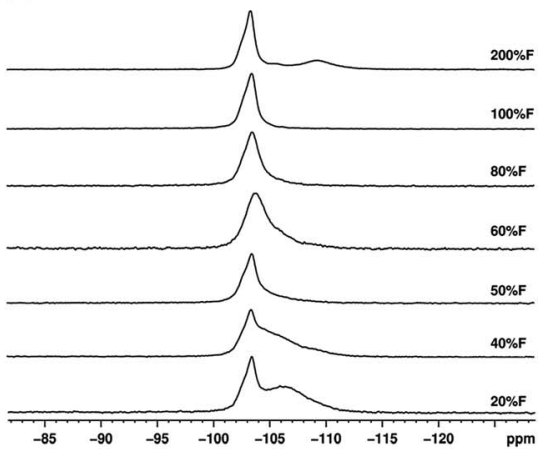

(c)

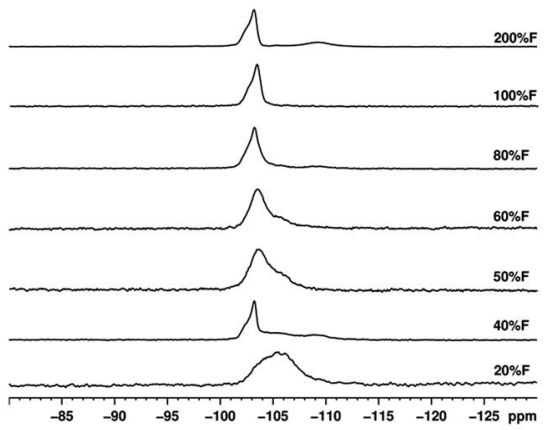

(d)

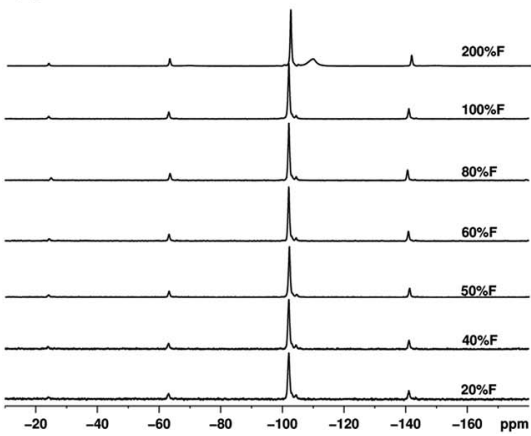

Fig. $6{ }^{19} \mathrm{~F}$ MAS-NMR spectra of FHA heat treated at different temperatures (a) $300{ }^{\circ} \mathrm{C}$ main resonance centered at -103.0 to -107.0 ppm corresponding to the $\mathrm{F}^{-}$in apatite structure, $-109.0 \mathrm{ppm}$ in $200 \% \mathrm{~F}$ corresponding to $\mathrm{CaF}_{2},-123$ ppm in $20 \% \mathrm{~F}$ is an impurity (b) $600{ }^{\circ} \mathrm{C}$ the main resonance at around $-103.0 \mathrm{ppm}$ and showing asymmetric line shape (c) $750{ }^{\circ} \mathrm{C}$ similar to $600^{\circ} \mathrm{C}$ and (d) $900{ }^{\circ} \mathrm{C}$ main resonance at $-102.0 \mathrm{ppm}$ corresponding to the $\mathrm{F}^{-}$in apatite structure with high crystallinity. 
Table $2{ }^{19} \mathrm{~F}$ MAS-NMR spectra deconvolution. The assignment is explained in the discussion text

\begin{tabular}{lllll}
\hline & $\begin{array}{l}\text { F rich region } \\
(\mathrm{ppm})\end{array}$ & $\begin{array}{l}\text { Integral } \\
(\%)\end{array}$ & $\begin{array}{l}\text { F deficient } \\
\text { region (ppm) }\end{array}$ & Integral (\%) \\
\hline $\mathbf{6 0 0}{ }^{\circ} \mathrm{C}$ & & & & \\
$20 \% \mathrm{~F}$ & -103.3 & 33 & -106.4 & 67 \\
$40 \% \mathrm{~F}$ & -103.4 & 36 & -105.7 & 64 \\
$50 \% \mathrm{~F}$ & -103.4 & 70 & -105.7 & 30 \\
$60 \% \mathrm{~F}$ & -103.8 & 61 & -105.2 & 39 \\
$80 \% \mathrm{~F}$ & -103.5 & 73 & -104.3 & 27 \\
$100 \% \mathrm{~F}$ & -103.3 & 100 & N/A & 0 \\
& & & & \\
$750{ }^{\circ} \mathrm{C}$ & & 7 & -105.6 & 93 \\
$20 \% \mathrm{~F}$ & -103.6 & 45 & -105.7 & 55 \\
$40 \% \mathrm{~F}$ & -103.1 & 70 & -105.8 & 30 \\
$50 \% \mathrm{~F}$ & -103.6 & 68 & -105.5 & 32 \\
$60 \% \mathrm{~F}$ & -103.5 & 83 & -105.8 & 9 \\
$80 \% \mathrm{~F}$ & -103.1 & 100 & N/A & 0 \\
$100 \% \mathrm{~F}$ & -103.3 & & & \\
${ }^{a} \mathrm{Contains}$ & $8 \% \mathrm{CaF}_{2}$. & & & \\
\hline
\end{tabular}

was seen as formation of the fluorapatite and $\beta$-TCP phase. Fig. 7 illustrates the proposed mechanism of the fluoride incorporation using the example of two selected FHA compositions, 20 and $40 \% \mathrm{~F}$. The $\beta$-TCP percentage comes from the XRD refinement data (Fig. 3 ) and the Fr and Fd percentage were calculated by ${ }^{19} \mathrm{~F}$ NMR deconvolution results (Table 2).

As seen from the Fig. 7, at the lowest heat-treatment temperature $300{ }^{\circ} \mathrm{C}$, the $\mathrm{F}^{-}$ions substitute for the $\mathrm{OH}^{-}$ groups and distribute randomly in the c channel forming $\mathrm{F}-\mathrm{OH}$ solid solution (SS stage). However, this SS stage is not thermally stable, a separation into an $\mathrm{Fr}$ and Fd is observed on increasing the heat-treatment temperature to $600^{\circ} \mathrm{C}$, as depicted in Fig. 6 . It is thought that the higher heat treatment temperature promotes the $\mathrm{F}^{-}$ions diffusion and separation from the random $\mathrm{F}-\mathrm{OH}$ mixture, some separated $\mathrm{F}^{-}$ions accumulate to form the $\mathrm{F}$ rich region. The rest of $\mathrm{F}^{-}$-ions are still mixed with

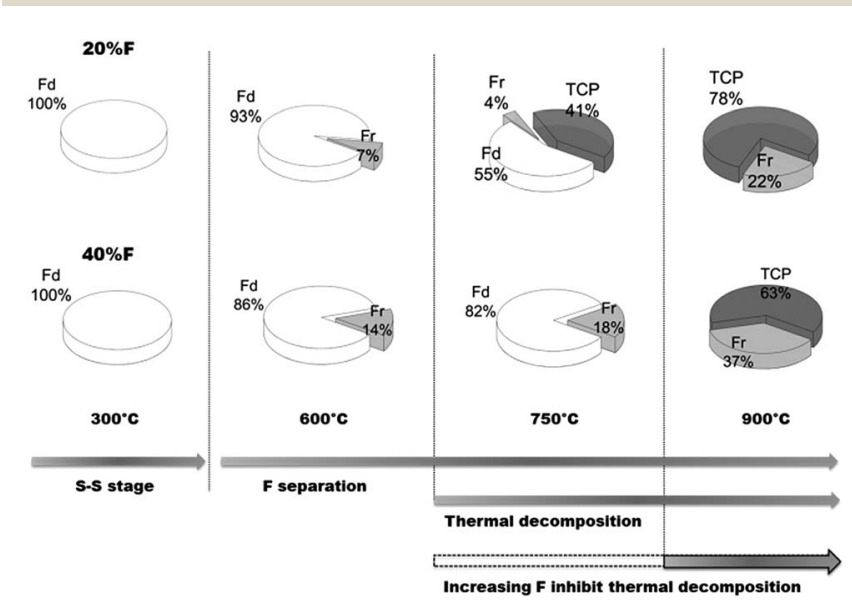

Fig. 7 Compositions changing of 20 and $40 \% \mathrm{~F}$ samples with increasing heat-treatment temperature from 300 to $900{ }^{\circ} \mathrm{C}$. The $\beta$ TCP percentage comes from the XRD refinement data (Fig. 3) and the $\mathrm{Fr}$ and $\mathrm{Fd}$ percentage were calculated by ${ }^{19} \mathrm{~F}$ NMR deconvolution results (Table 2).
$\mathrm{OH}$ groups in an $\mathrm{F}-\mathrm{OH}$ solid solution mode but with lower $\mathrm{F}^{-}$ concentration; this is proposed to be the $\mathrm{F}^{-}$deficient region. Further increasing heat-treatment temperature to $750^{\circ} \mathrm{C}$ causes thermal decomposition of the apatite phase to $\beta$-TCP. Both the $\mathrm{F}^{-}$separation and apatite thermal decomposition processes evolve as the temperature of heat treatment increases. Eventually, at $900{ }^{\circ} \mathrm{C}$, due to the combination of these two processes, all the samples are consist of $\beta$-TCP and $\mathrm{F}^{-}$rich apatite phases, as depicted in Fig. 7. Noteworthy, increasing the F\% in the hydroxyapatite postpones the starting of the apatite thermal decomposition. For example, in the Fig. 7, 20\% F sample starts to show the $\beta$-TCP phase at $750{ }^{\circ} \mathrm{C}$, while in $40 \%$ sample, $\beta$-TCP phase only can be found at $900{ }^{\circ} \mathrm{C}$.

Details of these stages and quantitative information are discussed below.

\section{Solid solution stage and separation in FHA identified by ${ }^{19} \mathrm{~F}$ MAS-NMR}

Formation of different types of FHA solid solution that are proposed in the previous sections were observed from the XRD and solid state NMR, in particular ${ }^{19} \mathrm{~F}$ NMR. The reduction of $a$ axis with increasing F\% (Fig. 2) agrees well with the different substitution level of $\mathrm{F}$ ions for $\mathrm{OH}$ groups in $\mathrm{c}$ channel, which causes the $a$ axis shrinkage due to the smaller $\mathrm{F}^{-}$ions replacing the larger $\mathrm{OH}^{-}$groups. In ${ }^{19} \mathrm{~F}$ NMR spectra, on increasing $\mathrm{F} \%$ the ${ }^{19} \mathrm{~F}$ NMR CS shifts downfield due to the influence of the neighboring atoms, since the three $\mathrm{Ca}(\mathrm{II})$ cations are identical, the major impact on the $\mathrm{F}^{-}$'s chemical environment must be the adjacent $\mathrm{F}^{-}$or $\mathrm{OH}^{-}$groups. The linear change in $a$ axis at the same treatment temperature indicates the change in the $\mathrm{F}^{-}$$\mathrm{F}^{-}$or $\mathrm{F}^{-}-\mathrm{OH}^{-}$distance in the channel, which perturbs the electron density in the shell of the fluorine atom. Therefore the length between $\mathrm{F}^{-}-\mathrm{F}^{-}$and $\mathrm{F}^{-}-\mathrm{HO}^{-}$results in the ${ }^{19} \mathrm{~F}$ NMR CS change. Here, the ${ }^{19} \mathrm{~F}$ NMR CS change is due to the close proximity of the $\mathrm{H}$ atom in the $\mathrm{OH}$ group. A similar effect seen in the linear correlation between CS and metal cation-fluorine distances was reported by Boden et al. ${ }^{23}$

Fig. 8 shows ${ }^{19} \mathrm{~F}$ NMR CS plotted against the F\%. A correlation between ${ }^{19} \mathrm{~F}$ NMR CS and $\mathrm{F} \%$ for $300{ }^{\circ} \mathrm{C}$ samples (Fig. 8) was found for the entire fluoride substitution range when fitted by the exponential decay function (eqn (1)) with $R^{2}=1.000, y_{0}=$ -103.5 , the decay constant $1 / t_{1}=1 / 21.88$ and the initial value $A_{1}$ $=-7.9907$. The fitting curve is named "SS fitting". It is also remarkable that the data on ${ }^{19} \mathrm{~F} \mathrm{CS}$ by Braun and Jana ${ }^{24}$ are in excellent agreement with the proposed correlation in Fig. 8.

$$
y-y_{0}=A_{1} \exp \left(-\frac{x}{t_{1}}\right)
$$

Small deviations between Braun and Jana work ${ }^{24}$ and SS fitting curve could be explained that Braun et al. introduced $\mathrm{Na}^{+}$ ions during the sample synthesis and the $\mathrm{Na}^{+}$could dope in to the apatite structure and substitute for $\mathrm{Ca}$ (II) $s i t e,{ }^{25}$ which is close enough to affect $\mathrm{F}^{-}$chemical environment causing ${ }^{19} \mathrm{~F}$ NMR CS change. In this project, the system is kept as simple as possible to avoid any anion or cation which could substitute 


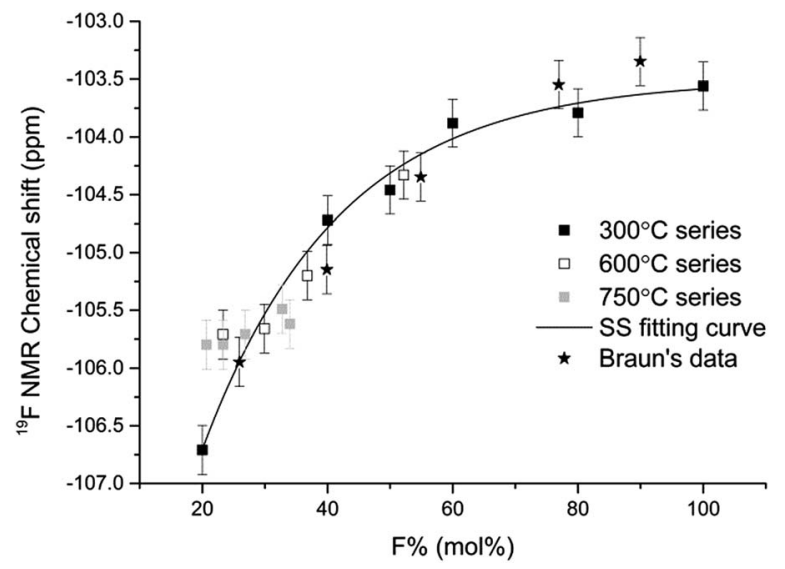

Fig. $8{ }^{19} \mathrm{~F}$ NMR chemical shifts plotted against F\% and the fitting curve of the $300{ }^{\circ} \mathrm{C}$ series (SS fitting curve): four sets of data are presented: three of them from the project $\left(300,600\right.$ and $750{ }^{\circ} \mathrm{C}$ series), and the fourth set of data from Braun's work is also plotted for comparison.

into apatite structure. The potential application of the found correlation curve is to evaluate the degree of fluoridation in FHA solid solution by using ${ }^{19} \mathrm{~F}$ NMR.

With increasing the heat-treatment temperature up to 600 and $750{ }^{\circ} \mathrm{C},{ }^{19} \mathrm{~F}$ NMR spectra show both CS change and asymmetric line shape, which indicates the higher heat treatment temperature causes disturbance of the $\mathrm{F}^{-}$ions local structure. Two main resonances have been observed after the deconvolution (Table 2); $-103.0 \mathrm{ppm}$ corresponding to the $\mathrm{F}$ in the $\mathrm{Fr}$ region. The resonance around -104.0 to $-106.0 \mathrm{ppm}$ is assigned to the fluorine $\mathrm{Fd}$ region, which represents $\mathrm{F}^{-}$ions and $\mathrm{OH}^{-}$groups mixed along the c channel forming the $\mathrm{F}^{-}$ $\mathrm{OH}^{-}$solid solution. The presence of the two different $\mathrm{F}^{-}$ chemical environments on heat treatment implies that high temperature causes the $\mathrm{F}^{-}$separation from the $\mathrm{F}^{-}-\mathrm{OH}^{-}$solid solution following by the formation of the $\mathrm{Fr}$ and $\mathrm{Fd}$ regions. The amount of these regions are calculated by ${ }^{19} \mathrm{~F}$ NMR deconvolution and shown in Fig. 9.

It is clear that with increasing heat treatment temperature, the amount of Fr\% (black bar) increases and Fd\% (grey bar) decreases. Based on the XRD results, our samples only contain apatite and $\beta$-TCP phases, and apatite structure is the only phase that could accommodate the $\mathrm{F}^{-}$ions, so the total fluorine content in each sample is constant at the different heat treatment temperatures. Heating temperature could promote the $\mathrm{Fr}$ region formation due to the transformation of $\mathrm{F}^{-}$ions from $\mathrm{Fd}$ to $\mathrm{Fr}$ region. The extreme examples are shown in $900{ }^{\circ} \mathrm{C}$, where more than $95 \%$ of $\mathrm{F}^{-}$ions in the samples formed the $\mathrm{Fr}$ region and left the Fd region decompose to $\beta$-TCP. This is confirmed by the ${ }^{19} \mathrm{~F}$ NMR and XRD at $900{ }^{\circ} \mathrm{C}$. The $95 \%$ Fr structure corresponding to the relatively narrow line shape at $-102.0 \mathrm{ppm}$ (fwhm $=0.6 \mathrm{ppm})$ in ${ }^{19} \mathrm{~F}$ NMR spectra (Fig. 6(d)) implies the highly ordered and therefore crystalline apatite structure. This could be distinguished from the CS at $-103.0 \mathrm{ppm}$ assigned to $\mathrm{F}^{-}$in the $\mathrm{Fr}$ region but with poorer crystalline structure (Fig. 6(a)-(c)).

The main implication of this result is that heat treatment of FHA powders at the temperature of $900{ }^{\circ} \mathrm{C}$ and above leads to

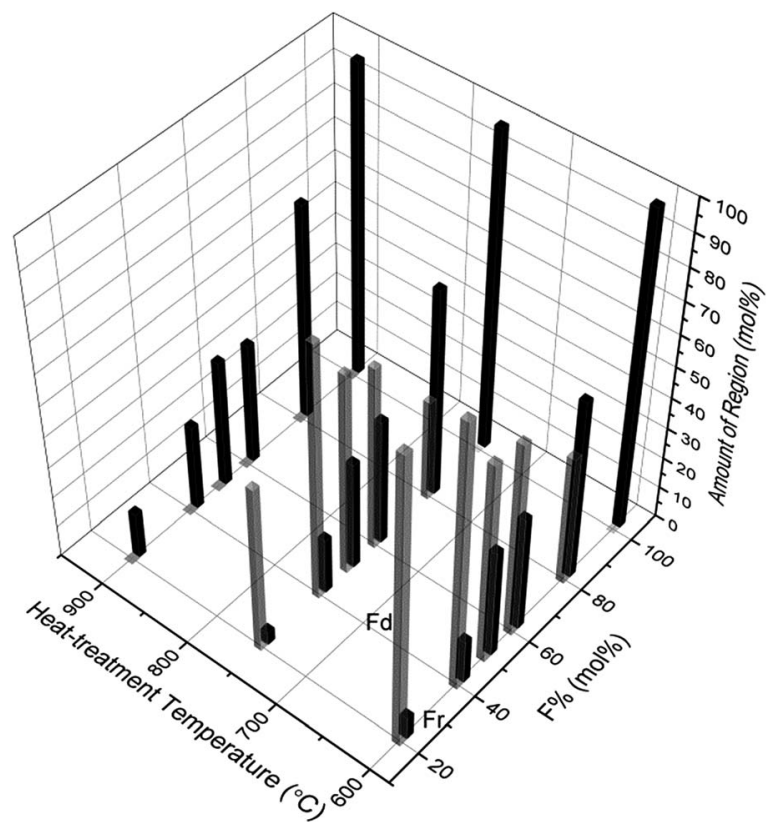

Fig. 9 Amount of $\mathrm{F}$ deficient region ( $\mathrm{Fd}$ ) and $\mathrm{F}$ rich region ( $\mathrm{Fr}$ ) of all samples at heat-treatment temperature at 600,750 and $900{ }^{\circ} \mathrm{C}$ (grey bar Fd; black bar Fr).

a segregation of the fluorapatite from the solid solution. This explains the results of the recent report by Campillo et al. studied HA fluoridation using Raman scattering. ${ }^{26}$ The peak position of the $\mathrm{PO}_{4} v_{1}$ mode in Raman spectra did not show any difference with variation in fluoridation level ranging from 10 to $95 \%$. However, the final heat treatment temperature of the experimental samples after fluoridation was at $1000{ }^{\circ} \mathrm{C}$ and the segregation of the fluoride rich apatite out of the solid solution must have occurred. This conclusion also can be shown by the change in linewidth of ${ }^{31} \mathrm{P}$ NMR peaks (Fig. 5). The linewidth of the ${ }^{31} \mathrm{P}$ centered at $2.8 \mathrm{ppm}$ is determined by the degree of crystallinity of $\mathrm{PO}_{4}$ groups. ${ }^{27}$ The peaks narrowing from $1.00 \mathrm{ppm}$ to $0.22 \mathrm{ppm}$ at elevated heat treatment temperature from 300 to $900{ }^{\circ} \mathrm{C}$ reflects the increasing crystallinity of apatite phase. When the heat treatment temperature lower than $900{ }^{\circ} \mathrm{C}$, the $\mathrm{F} \%$ also shows a clear impact on the degree of crystallinity of the $\mathrm{PO}_{4}$ groups, but further increasing heating temperature at $900{ }^{\circ} \mathrm{C}$ eliminates this influence of the $\mathrm{F}$ content on the ${ }^{31} \mathrm{P}$ NMR linewidth. ${ }^{31} \mathrm{P}$ NMR shows a constant fwhm $(0.22 \mathrm{ppm})$ with fluoridation level from 20 to $200 \%$. This is another evidence of the segregation of the fluorapatite from the solid solution at $900{ }^{\circ} \mathrm{C}$.

At $900{ }^{\circ} \mathrm{C}$, there is a second $\mathrm{F}$ environment corresponding to the ${ }^{19} \mathrm{~F}$ CS at $-104.5 \mathrm{ppm}$ with very small proportion, $c a$. $5 \%$. This signal could be the $\mathrm{F}^{-}$affected by the residual $\mathrm{OH}^{-}$in the $\mathrm{F}^{-}$rich region. The existence of the residual $\mathrm{OH}$ could be because of very small amount of $\mathrm{OH}^{-}$groups trapped in the FA region and forming $\mathrm{F}^{-}-\mathrm{OH}^{-}$mixture domain in the pure FA matrix. According to SS fitting (Fig. 8), the -104.5 ppm signal could correspond to the $50 \%$ F FHA.

The amount of the different $\mathrm{F}$ regions is also affected by the nominal $\mathrm{F} \%$ in the sample. At the same heat treatment 
Table $3 \mathrm{~F} \%$ in F deficient region and the corresponding ${ }^{19} \mathrm{~F}$ NMR CS

\begin{tabular}{|c|c|c|c|c|}
\hline \multirow[b]{2}{*}{$\begin{array}{l}\text { F\% } \\
(\mathrm{mol} \%)\end{array}$} & \multicolumn{2}{|l|}{$600{ }^{\circ} \mathrm{C}$} & \multicolumn{2}{|l|}{$750^{\circ} \mathrm{C}$} \\
\hline & $\begin{array}{l}\mathrm{F} \%_{\mathrm{Fd}} \\
(\mathrm{mol} \%)\end{array}$ & $\begin{array}{l}{ }^{19} \mathrm{~F} \\
\mathrm{CS}(\mathrm{ppm})\end{array}$ & $\mathrm{F} \%_{\mathrm{Fd}}(\mathrm{mol} \%)$ & $\begin{array}{l}{ }^{19} \mathrm{~F} \\
\mathrm{CS}(\mathrm{ppm})\end{array}$ \\
\hline 20 & 14 & -106.4 & 34 & -105.6 \\
\hline 40 & 30 & -105.7 & 27 & -105.7 \\
\hline 50 & 23 & -105.7 & 23 & -105.8 \\
\hline 60 & 36 & -105.2 & 32 & -105.5 \\
\hline 80 & 52 & -104.3 & 20 & -105.8 \\
\hline 100 & 0 & $\mathrm{~N} / \mathrm{A}$ & 0 & $\mathrm{~N} / \mathrm{A}$ \\
\hline
\end{tabular}

temperature, in general, with increasing $\mathrm{F} \%$ the amount of $\mathrm{Fr}$ region increases. This can be understood that the $\mathrm{F}^{-}$ions in the structure are preferentially clustered together forming pure $\mathrm{F}^{-}$

\section{P MAS-NMR}

(a)
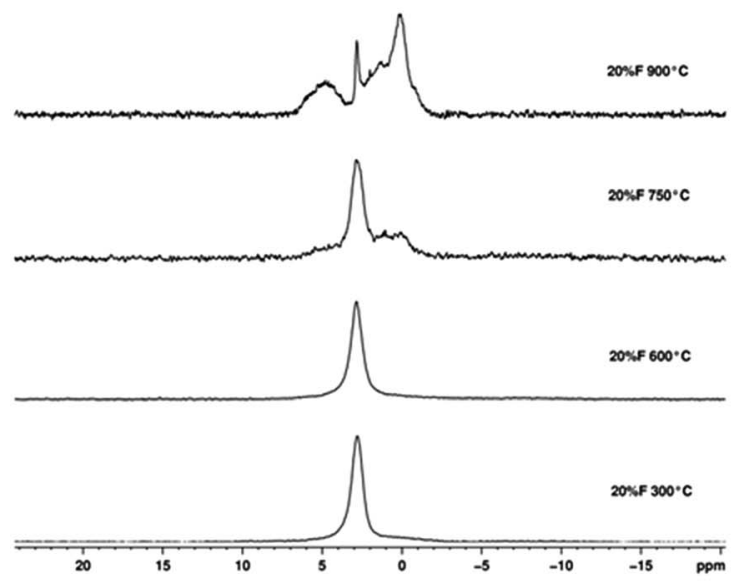

(b)
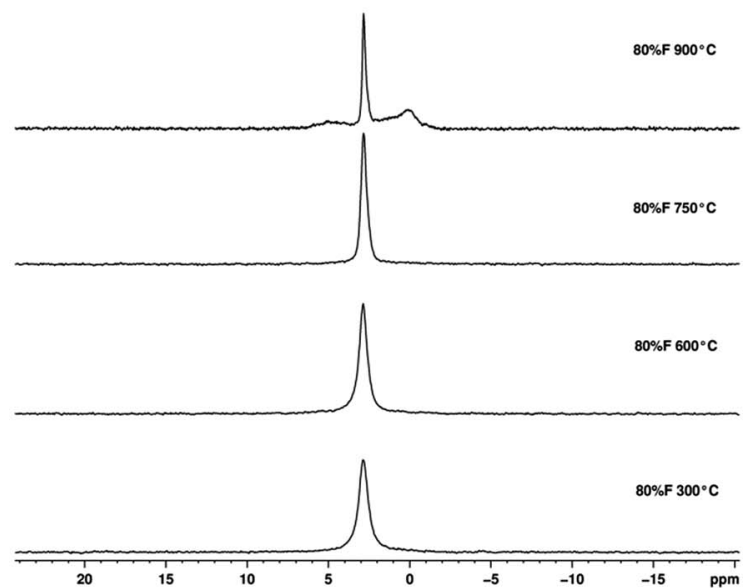

Fig. $10{ }^{31} \mathrm{P}$ MAS-NMR spectra of 20 and $80 \% \mathrm{~F}$ at different heat treatment temperature (a) $20 \% \mathrm{~F}$ heat treated from 300 to $900{ }^{\circ} \mathrm{C}, \beta$ TCP are observed from $750{ }^{\circ} \mathrm{C}$ (b) $80 \% \mathrm{~F}$ heat treated from 300 to $900{ }^{\circ} \mathrm{C}, \beta$-TCP are observed at $900{ }^{\circ} \mathrm{C}$. "chain" of fluorapatite. In ${ }^{19} \mathrm{~F}$ NMR spectra, this $\mathrm{F}^{-}$chain in $\mathrm{Fr}$ structure produces consistent resonance at $-103.0 \mathrm{ppm}$. However Fd region is more complicated, the actual fluoride substitution in solid solution in Fd region are calculated in Table 3. The variation in $\mathrm{F}_{\mathrm{Fd}_{\mathrm{F}}}$ in Fd structure explain the $\mathrm{CS}$ of the second ${ }^{19} \mathrm{~F}$ NMR peak between -104.0 to $-106.0 \mathrm{ppm}$. The data in Table 3 also are plotted in Fig. 8. These two sets of data have fairly good agreement with the SS fitting curve deduced from $300{ }^{\circ} \mathrm{C}$ data, except the $40 \% \mathrm{~F}$ in $750{ }^{\circ} \mathrm{C}$ shows large deviation from the SS fitting, which could due to the poor deconvolution.

\section{Thermal decomposition (heat-treatment temperature above $\left.750{ }^{\circ} \mathrm{C}\right)$}

Thermal stability of FHA was reported previously, decomposition has been found to occur at 1000-1100 ${ }^{\circ} \mathrm{C}$. However, we found that the FHA are not as stable as it has been previously reported, for instance the $20 \% \mathrm{~F}$ sample starts decomposing at $750{ }^{\circ} \mathrm{C}$. Increasing in $\mathrm{F} \%$ inhibits the $\beta$-TCP phase formation. In ${ }^{31}$ P NMR spectra (Fig. 10), it is clearly shown that $20 \%$ F sample decomposed partially to $\beta$-TCP at $750{ }^{\circ} \mathrm{C}$, while at higher $\mathrm{F} \%$ up to $80 \%$, the decomposition to $\beta$-TCP only starts at $900{ }^{\circ} \mathrm{C}$. This implies that increasing $\mathrm{F} \%$ inhibits apatite decomposition to $\beta$ TCP. The XRD results (Fig. 1(b)) also agree with this conclusion.

The highest heat-treatment temperature in this project is $900{ }^{\circ} \mathrm{C}$. At this stage, both $a$ axis parameters (Fig. 2) and ${ }^{19} \mathrm{~F}$ CS (Fig. 6(d)) show independence of the F\%. For all samples from $20 \%$ to $100 \% \mathrm{~F}$ the $a$ axis was found to be stable at $9.380 \AA$, and the same ${ }^{19} \mathrm{~F} \mathrm{CS}$ at $-102.0 \mathrm{ppm}$ was observed. This implies that the apatite phase contains the similar $\mathrm{F}^{-}$environment in the $\mathrm{c}$ channel at all these substitutions, which is solely Fr structure in all samples at $900{ }^{\circ} \mathrm{C}$.

\section{Conclusions}

A series of FHA samples from 0 to $200 \% \mathrm{~F}$ have been synthesized by the solution route followed by heating, in air, at different temperatures $\left(300\right.$ to $900{ }^{\circ} \mathrm{C}$ ). Powder XRD, ${ }^{31} \mathrm{P}$ and ${ }^{19} \mathrm{~F}$ NMR were used to characterize the synthesized powders. The comprehensive data were obtained and allowed for the first time a detailed analysis which gave rise to a new theory of the structure evolution of hydroxyfluorapatite solid solution: a separation of the FHA for the fluoride-deficient and fluoriderich domains, in addition to thermal decomposition, was found depending on the fluoride substitution level and heat treatment temperature. A nonlinear relation between ${ }^{19} \mathrm{~F}$ NMR $\mathrm{CS}$ and $\mathrm{F} \%$ is found in $300{ }^{\circ} \mathrm{C}$ series, and is applicable to different heat treatments of FHA solid solutions. ${ }^{19} \mathrm{~F}$ NMR CS

\begin{tabular}{llll} 
Table 4 & ${ }^{19} \mathrm{~F}$ NMR CS assignment (ppm) & \\
\hline-102.0 & -103.0 & -104.0 to -106.0 & -109.0 \\
\hline F-F*-F high & $\begin{array}{l}\text { F-F*-F low } \\
\text { crystallinity }\end{array}$ & $\begin{array}{l}\text { F-F }-F^{*}-\mathrm{OH} \text { or } \mathrm{OH}-\mathrm{F}^{*}-\mathrm{OH} \\
\text { crinity }\end{array}$ & $\begin{array}{l}\text { SS stage } \\
2\end{array}$
\end{tabular}


also could be used to distinguish whether the $\mathrm{F}^{-}$is in the low degree of crystallinity environment $(-103.0 \mathrm{ppm})$ or the high crystalline environment $(-102.0 \mathrm{ppm})$ in FA structure. Increasing $\mathrm{F} \%$ in the FHA inhibits the thermal decomposition of HA which gives rise to the $\beta$-TCP. All the ${ }^{19} \mathrm{~F}$ NMR CS found in this project are summarized in Table 4 .

\section{Conflict of interest}

The authors declare no competing financial interest.

\section{Acknowledgements}

We thank Mr Richard Sweeney and Dr Victoria Bemmer from Department of Materials in Imperial College London for powder XRD experiments, and Dr Nicola Doebelin from RMS Foundation, Switzerland, for helping with X-ray refinement. We also thank Dr Harold Toms who runs the Queen Mary University of London NMR service and Department of Chemistry in Imperial College London for support of the experimental studies.

\section{References}

1 J. Carsten and B. Marco, Biomaterials, 1996, 17, 5.

2 L. M. Rodríguez-Lorenzo, J. N. Hart and K. A. Gross, Biomaterials, 2003, 24, 9.

3 (a) L. Jha, S. Best, J. Knowles, I. Rehman, J. Santos and W. Bonfield, J. Mater. Sci.: Mater. Med., 1997, 7; (b) H. W. Kim, Y. J. Noh, Y. H. Koh and H. E. Kim, J. Mater. Sci.: Mater. Med., 2003, 6.

4 J. P. Yamasaki, Y. Yoshida, M. Okazaki, A. Shimazu, T. Uchida and T. Kubo, J. Biomed. Mater. Res., 2002, 62, 7.

5 (a) J. C. Elliott, Structure and Chemistry of the Apatites and Other Calcium Orthophosphates, ELSEVIER, 1994; (b) J. C. Elliott, R. M. Wilson and S. E. P. Dowker, Adv. X-Ray Anal., 2002, 45, 10.

6 K. Sudarsanan, P. E. Mackie and R. A. Young, Mater. Res. Bull., 1962, 7, 8.

7 I. Nikcevic, V. Jokanovic, M. Mitric, Z. Nedic, D. Makove and D. Uskokovic, J. Solid State Chem., 2004, 177(10), 2565-2574.

8 C. C. Wua, S. T. Huang, T. W. Tseng, Q. L. Rao and H. C. Lin, J. Mol. Struct., 2010, 5.

9 I. Manjubala, M. Sivakumar and S. N. Nikkath, J. Mater. Sci., 2001, 36, 6.

10 (a) M. N. Bachhav, S. R. Chang, A. McFarland, E. A. Marquis and B. Clarkson, Microsc. Microanal., 2013, 19, 2; (b) L. M. Rodriguez-Lorenzo, J. N. Hart and K. A. Gross, Biomaterials, 2003, 24, 9.

11 (a) F. Freund and R. M. Knobel, J. Chem. Soc., Dalton Trans., 1976, 5; (b) S. M. Barinova, L. I. Shvornevab, D. Ferroc,
I. V. Fadeevaa and S. V. Tumanova, Sci. Technol. Adv. Mater., 2004, 5, 5.

12 K. J. D. MacKenzie and M. E. Smith, Multinuclear Solid-State Nuclear Magnetic Resonance of Inorganic Materials, Elsevier Science Limited, 2002.

13 (a) J. P. Yesinowske and M. J. Mobley, J. Am. Chem. Soc., 1983, 105, 3; (b) R. M. Wilson, J. C. Elliot and E. P. Dowker, Biomaterials, 2005, 11; (c) Y. Wu, M. J. Glimcher, C. Rey and J. L. Ackerman, J. Mol. Biol., 1994, 244, 3; (d) W. P. Rothwell, J. S. Waugh and J. P. Yesinowski, J. Am. Chem. Soc., 1980, 102, 7; (e) J. Chen, Z. Yu, P. Zhu, J. Wang, Z. Gan, J. Wei, Y. Zhao and S. Wei, J. Mater. Chem. B, 2015, 3, 5; (f) K. S. K. Lin, Y. H. Tseng, Y. Mou, Y. C. Hsu, C. M. Yang and J. C. C. Chan, Chem. Mater., 2005, 17, 7; (g) P. N. Gunawidjaja, A. Y. H. Lo, I. IzquierdoBarba, A. García, D. Arcos, B. Stevensson, J. Grins, M. Vallet-Regí and M. Edén, J. Phys. Chem. C, 2010, 114, 10; (h) R. J. Kirkpatrick and R. K. Brow, Solid State Nucl. Magn. Reson., 1995, 5, 13.

14 P. James, J. P. Yesinowski and H. Eckert, J. Am. Chem. Soc., 1987, 109, 9.

15 (a) M. Okazaki, Y. Miake, H. Tohda, T. Yanagisawa, T. Matsumato and J. Takahashi, Biomaterials, 1991, 20, 6; (b) M. Braun, P. Hartmann and C. Jana, J. Mater. Sci.: Mater. Med., 1995, 6, 4.

16 (a) H. E. Mason, F. M. McCubbin, A. Smirnov and B. L. Phillips, Am. Mineral., 2009, 94, 10; (b) C. Liao, F. Lin, K. Chen and J. Sun, Biomaterials, 1999, 20, 7.

17 S. W. K. Kweh, K. A. Khor and P. Cheang, J. Mater. Process. Technol., 1999, 89-90, 5.

18 G. Penel, G. Leroy, C. Ret, B. Sombret, J. P. Huvenne and E. Bres, J. Mater. Sci.: Mater. Med., 1997, 8, 6.

19 D. Nicola and K. Reinhard, J. Appl. Crystallogr., 2015, 48, 7.

20 D. Massiot, F. Fayon, M. Capron, I. King, S. L. Calvé, B. Alonso, J. O. Durand, B. B. Gan and G. Hoatson, Magn. Reson. Chem., 2002, 40, 7.

21 J. L. Miquel, L. Facchini, A. P. Legrand, C. Rey and J. Lemaitre, Colloids Surf., B, 1990, 45, 7.

22 X. Marchandise, P. Belgrand and E. Andre Pierre, Magn. Reson. Med., 1992, 28, 8.

23 N. Boden, P. K. Kahol, A. Mee, M. Mortimer and G. N. Peterson, J. Magn. Reson., 1983, 54, 8.

24 M. Braun and C. Jana, Chem. Phys. Lett., 1995, 245, 4.

25 D. Laurencin, A. Wong, W. Chrzanowski, J. C. Knowles, D. Qiu, D. M. Pickup, R. J. Newport, Z. Gan, M. J. Duere and M. E. Smith, Phys. Chem. Chem. Phys., 2010, 12, 12.

26 M. Campillo, P. D. Lacharmoise, J. S. Reparaz, A. R. Goñi and M. Valiente, J. Chem. Phys., 2010, 6.

27 M. Bohner and J. Lemaitre, J. Mater. Sci.: Mater. Med., 1996, 7,5 . 